ISSN: $2594-4827$

\title{
FORMAÇÃO NO E PARA O TRABALHO'
}

Sandra Soares Della Fonte ${ }^{2}$

\section{RESUMO}

Tendo em vista a proposta de alinhamento conceitual do ProfEPT, destaca-se a contribuição de Marx quanto à relação entre formação humana e trabalho. Esse autor apresenta o trabalho como uma ação que instaura relações do ser humano com a natureza e com outros seres humanos. O trabalho representa, assim, um agir formativo sob relações historicamente determinadas. Quando analisa as formas da produção no capitalismo, Marx aponta que o trabalho explorado engendra uma formação unilateral. Contudo, a produção mecanizada traz gérmens não apenas de uma formação omnilateral, mas também de uma educação do futuro que articula educação intelectual, física/estética e tecnológica a partir dos interesses dos trabalhadores. Desde seu estabelecimento em 2008, os Institutos Federais de Educação, Ciência e Tecnologia têm ensaiado, em meio a contradições diversas, experiências nesse horizonte políticopedagógico. Por essa razão, podem apresentar-se como agente importante na defesa da frágil, mas necessária perspectiva de educação integrada.

Palavras-chave: Educação profissional e tecnológica; trabalho; formação humana; Marx.

\begin{abstract}
Taking into account the proposed conceptual alignment by ProfEPT, it high lights the contribution of Marx as for the relation between human formation and labour. This author presents labour as anaction that establishes relations between the human being with nature and with other human beings. Labour represents, the refore, a formative act that occurs with in historically determined relationship. When he analyzes the forms of production in capitalism, Marx points out that the explored labour builds a unilateral formation. However, mechanized production brings elements notonly of a comprehensive formation, but also of na education of the future that articulates intellectual, physical / a esthetic and technological education from workers interests. Since their establishment in 2008, the Federal Institutes of Education, Science and Technology havetested, in themidst of contradictions, experiences in this politicalpedagogicalhorizon. For this reason, they can present them selves as an important agent in the defense of the fragile, but necessary perspective of integrate deducation.
\end{abstract}

Keywords: Professional and technological education; Labour; Human formation; Marx.

\footnotetext{
${ }^{1}$ Artigo produzido a partir da palestra apresentada no IV Seminário de Alinhamento Conceitual do ProfEPT, promovido pelo Programa de Pós-Graduação em Educação Profissional e Tecnológica (ProfEPT).

${ }^{2}$ Professora da Universidade Federal do Espírito Santo (UFES), atua no Programa de Pós-Graduação Mestrado Profissional em Ensino de Humanidades (IFES campus Vitória) e no Programa de PósGraduação em Educação da UFES. Endereço eletrônico: sdellafonte@ gmail.com
} 
No IV Seminário de Alinhamento Conceitual do Programa de Pós-Graduação em Educação Profissional e Tecnológicaem rede nacional (ProfEPT), realizado em novembro de 2018 na acolhedora cidade de Goiânia, foi proposto como tema da mesa de abertura "Formação no e para o trabalho". Confesso que, para definir minha possível contribuição para o debate, demorei-me um pouco na expressão "alinhamento conceitual".

$\mathrm{Na}$ atmosfera do resultado das eleições presidenciais e diante de pronunciamentos, no mínimo, preocupantes, do candidato eleito acerca da composição e orientação de seu governo, adotei uma posição quanto a essa expressão. Longe do sentido imediatode pôr-se em linha reta, enfileirar, propus conceber o alinhamentocomo a eleição de possíveis eixos conceituais de sustentação, atravessados por muitas tensões e diálogos abertos. Nesse sentido, alinhar é construir, a partir de uma diversidade teórico-política, uma espécie de conciliação, um acordo, tendo em vista um compromisso compartilhado a saber: o combate ao projeto (neo)liberal de educação escolar, que, a partir de 2019, promete vestir-se de traços mais agressivos e totalitários.

Nesse processo, ajustar e aguçar bases conceituais comuns não significa ter uma referência conceitual única, propósito inadequado diante da necessidade de arranjo de uma frente ampla de resistência e luta, mas fomentar debates que ajudem a estabelecer convergências das diferenças nesse amplo campo que Saviani (2007) denominou de "teorias educacionais contra-hegemônicas".

Nesta construção de pontos de encontros, considero que a contribuição marxista ocupa um lugar especial no alinhamento conceitual do ProfEPT. Parece-me que, a despeito das polêmicas que ela comporta no seio de sua própria tradição ao conceber o trabalho como princípio educativo (cf. LESSA, 2007; NOSELLA, 2007; SAVIANI, 2003; TUMOLO, 2005) e da sua condição ainda em construção, a proposta marxista é talvez a alternativa mais avançada e sistematizada em nossa luta contra um projeto que se limita a preparar e qualificar o trabalhador a partir dos interesses patronais. Com essa consideração, objetivo evidenciar a vitalidade da noção marxiana de omnilateralidade na relação que pode ser estabelecida entre formação humana e trabalho. 


\section{TRABALHO: O APRIORISMO DA HONRA E DA DESONRA}

Há que se reconhecer que a contribuição de Marx se dá diante de uma história já em andamento. Relacionar a formação humana e o trabalho é uma tarefa que tem sido realizada há muito pela humanidade. Já na Antiguidade Clássica, o conflito entre os projetos de educação homérica e hesiodéica contemplava modos distintos de vincular formação e trabalho. Aproximadamente no século VIII a.C., Hesíodo cantou, em seu poema épico Os trabalhos e os dias:"Com trabalho os homens tornam-se ricos em rebanhos e opulentos, e trabalhando serás muito mais querido dos imortais e dos mortais: muito eles odeiam os ociosos. O trabalho não é nenhuma desonra; desonra é não trabalhar" (HESÍODO, 2012, p. 93-95). Ele complementa: "Se em teu peito o espírito aspira à riqueza, assim faz, e trabalha em trabalho sobre trabalho" (HESÍODO, 2012, p. 103). Os protagonistas do poema de Hesíodo vivem da terra, não contam com a ajuda de muitos escravos ou servos e, por isso, precisam do trabalho diário para sobreviver. Em contraste, em Homero, “[...] o foco principal da atenção são nobres guerreiros cuja relação com a dureza do trabalho agrícola está muito mediada" (MOURA, 2012, p. 25).

Assim, a contraposição entre o poeta da civilização heroica e o poeta da civilização agrícola expressa "[...] um conflito entre as duas tradições culturais, a dos aristocratas guerreiros e a do povo de produtores" (MANACORDA,1996, p. 45). Longe de encerrar-se nos contornos históricos da Grécia antiga, esse conflito atravessa os tempos e ganha configurações muito peculiares e complexas. A compreensão do trabalho como sofrimento e punição esteve, de um modo bastante peculiar, presente na maior parte das filosofias antiga e medieval. O ócio era tido como bom em si mesmo, pois, afinal, era prerrogativa de uma classe que, detentora de escravos ou servos, de fato, não precisava estar vinculada diretamente à produção. Por isso, o viés nobre e honroso do termo grego otiumem oposição ao qual se encontra o necotium, entendido como ocupação, trabalho e labuta.

As origens etimológicas de trabalho também reforçam sua aura de negatividade. Da língua latina vulgar, trabalho relaciona-se com tripalium, instrumento usualmente utilizado pelos romanos para as atividades agrícolas, mas também para torturar os escravos desobedientes. Por isso: "A tripalium se liga o verbo do latim vulgar 
tripaliare, que significa justamente torturar" (ALBORNOZ, 2000, p. 10). Trabalhoainda se vincula a palavra latina labor, quedenota esforço, sofrimento, dor, fadiga.

Por outro lado, em certa medida, essa visão pejorativa do trabalho é posta em xeque durante alguns momentos históricos. No Renascimento, há a valorização das chamadas artes mecânicas (alfaiataria e tecelagem, agricultura, arquitetura e alvenaria, ferraria, metalurgia, entre outras) que eram práticas e úteis em relação às artes liberais (trivium e quadrivium) que comportavam um saber de caráter especulativo, contemplativo, hermético (cf. ROSSI, 2001). A Reforma Protestante também participa, por outra via, dessa tendência de valorização do trabalho. Como demonstra Max Weber (1987), o espírito do capitalismo envolve uma ética de vida que condena o ócio e a preguiça e abraça uma orientação na qual o indivíduo vê a dedicação ao trabalho e a busca da riqueza como um dever moral.

Há, nesse contexto, uma inversão: o ócio e a vida contemplativa são condenados, e o trabalho é revestido de um elogio da vida ativa. Com o advento da sociedade burguesa, o esforço individual e ativo do indivíduo é enaltecido em detrimento da atitude contemplativa da nobreza e do clero. Não por acaso tal perspectiva também ganha expressão na identificação do trabalho como fonte de riqueza pelos economistas políticos ingleses do século XVIII.

Os ecos dessa tradição ressoam através dos tempos. Dois séculos depois, na Segunda Guerra Mundial, a frase "O trabalho liberta" foi colocada nos pórticos de vários campos de extermínio do regime nazista. Já no século XXI, em solo brasileiro, após o golpe parlamentar de 2016 que depôs a presidenta Dilma Roussef, ouvimos o primeiro discurso de Michel Temer insistir: "Não pense em crise, trabalhe".

Essas menções breves, cheias de lacunas e saltos históricos, apenas servem para ilustrar o quanto historicamente o trabalho oscila entre a virtude e o fardo, entre a punição e a fortuna. A meu ver, a inserção de Marx e também Engels nessa história permitiu o escape dessa armadilha de definir a priori a natureza do trabalho. 
ISSN: $2594-4827$

\title{
O TRABALHO FORMA E DEFORMA
}

\begin{abstract}
O trabalho é a fonte de toda riqueza, dizem os economistas políticos. Ele é isso - juntamente com a Natureza, que lhe fornece a matéria [Stoff] que ele transforma em riqueza. Mas é ainda infinitamente mais do que isso. Ele é a primeira condição fundamental de toda a vida humana e, com efeito, num grau tal que, em certo sentido, temos que dizer:ele criou o homem (ENGELS, 1991, p. 71).
\end{abstract}

Aceito a indicação de Michel Henry, um fenomenólogo marxista, que insiste que “O pensamento de Marx nos coloca diante da questão abissal: que é a vida?” (HENRY, 2015, p. 107). Viver é produzir as condições e os meios para existir. Esse é o fundamento da vida humana e, por essa razão, Marx e Engels (2007) insistem n'A ideologia alemã que é a vida que determina a consciência e não o contrário. O modo como seres humanos produzem esses meios não deve ser visto apenas na ótica da reprodução da sua existência física, mas como manifestação de suas vidas, um modo de vida determinado, com suas marcas históricas:

Tal como os indivíduos exteriorizam sua vida, assim são eles. O que eles são coincide, pois, com sua produção, tanto com $o$ que produzem como também com o modo como produzem. O que os indivíduos são, portanto, depende das condições materiais de sua produção (MARX; ENGELS, 2007, p. 87).

A estrutura do viverhumano diz respeito, assim, ao que produzimos para atender às nossas necessidades e ao arranjo relacionaldessa produção (relações sociais, relações com a natureza, relações com os instrumentos do trabalho).

A ação tipicamente humana de produzir sua vida chama-se trabalho. Os demais animais nascem com todo o aparato genético para desenvolver aquilo que são no tempo de vida singular de cada membro da espécie. Assim, um gato nasce com as inscrições genéticas que lhe garantem ser um gato; cada gato tem a chance de desenvolver essa "gatinidade" no tempo de sua existência. Portanto, os animais se relacionam com a natureza a partir de suas determinações biológico-hereditárias; por isso, não acumulam, transmitem e aperfeiçoam suas aprendizagens através das gerações. Em contraposição, o ser humano não nasce humano, ele faz-se humano; e oformar-se humano de cada um nunca esgota as possibilidades do humanizar-sejá existentes na história humana ou passíveis de ainda serem criadas. 
O formar-se humano só é possíveldevido ao trabalho. Aqui não é possível mais confundir trabalho com a ideia de emprego; estamos em um nível de discussão ontológica. Em uma passagem clássica, Marx afirma:

Antes de tudo, o trabalho é um processo de que participa o homem e a natureza, processo em que o ser humano, com sua própria ação, impulsiona, regula e controla seu intercâmbio material com a natureza. Defronta-se com a natureza como uma de suas forças. Põe em movimento as forças naturais de seu corpo - braços e pernas, cabeça e mãos -, a fim de apropriar-se dos recursos da natureza, imprimindo-lhes forma útil à vida humana. Atuando assim sobre a natureza externa e modificando-a, ao mesmo tempo modifica sua própria natureza (MARX, 1985, p. 211).

Essa citação necessita traz inúmeros elementos a serem considerados. Em primeiro lugar, o trabalho é a transformação da natureza pelo ser humano; em função de necessidades, o ser humano se apropria de objetos da natureza eos transforma. Assim, o trabalho diz respeito à essa ação criadora e criativa na qual, para sobreviver, o ser humano age e modifica a natureza, criando uma natureza humanizada. Entretanto, ele não faz isso isoladamente; por isso, o trabalho envolve uma dupla relação: com a natureza e com outro humano (MARX; ENGELS, 2007).

A tradição marxista chama de patrimônio cultural ao vasto mundo de "coisas" materiais e simbólicas que resultam do trabalho e que antes não existiam na natureza: ferramentas, instrumentos, técnicas, artefatos tecnológicos, crenças, comportamentos, conhecimentos, valores, habilidades etc.Em tudo que produz, o ser humano se coloca, isto é, ele se projeta, coloca o seu ser na sua criação. Portanto, toda produção cultural traz a marca do humano, materializa o nosso modo de existir em um determinado momento, corporifica o que se produz e como se produz a vida.

Para se tornar humana, cada nova geração precisará ser convidada a participar do mundo humano, pois a experiência propriamente humana não se inscreve no arcabouço genético da espécie; como mencionado, ela se materializa no mundo da cultura, no universo de produções nos quais mulheres e homens tatuam a estrutura do seu viveraté aquele momento. Assim, coloca-se imprescindível o processo de apreensão ativa das conquistas e produções no formar-se humano de cada nova geração, pois nelas se condensa o que somos nós ao longo da história. O acesso ao patrimônio cultural é condição de humanização. 
Ao transformar a natureza, o ser humano transforma a si própria, cria faculdades e capacidades que antes ele não possuía. Ao operar sobre a natureza, o ser humano muda a si mesmo; cria não apenas ummundo cultural fora de si, mas também cria a si como ser social/humano. Além disso, o ser humano não produz apenas forçado por necessidades imediatas, mas principalmente quando livre delas; assim "[...] o homem também forma, por isso, segundo as leis da beleza" (MARX, 2004, p. 85). Assim, somos produtores do imediatamente útil, mas também do inútil, isto é, daquilo que não tem necessariamente uma aplicação imediata.

Nesse sentido, atualiza-se, sobre bases materialistas, aquilo que Hegel (2011) em sua Fenomenologia do espírito insistira: o trabalho forma, modela, estrutura; ele é Bildung, ou seja, agir formativo. Ele forma o objeto e o sujeito do trabalho. O trabalho forma, modela, estrutura objetos naturais (nega a natureza e a modifica). Mas não apenas isso. O trabalho forma o objeto e o próprio sujeito do trabalho, ao permitir que este se projeta no objeto exteriorizado; o sujeito se forma quando inscreve o seu existir na sua obra e dela se apropria. Hegel já indicava aquilo que Vinícius de Moraes chamava, em seu poema $O$ operário em construção, de "fato extraordinário" desconhecido: "Que o operário faz a coisa/ E a coisa faz o operário".

Por sua vez, na perspectiva marxiana, o ser humano não tem uma essência definida a priori de seu existir, de seu fazer-se. Compreender o que é o ser humano implica indagar como ele se faz, como vive, o que produz, como produz,e, portanto, que tipo de formação propicia o trabalho em um dado momento.

Especificamente nas formas de produção social assumidas pelo capitalismo, Marx (1985) observa uma formação unilateral do trabalhador. Na manufatura, quando um capitalista reúne na sua fábrica os operários e cada um executa as diferentes operações que criam a mercadoria, o trabalhador é aprisionado a uma única operação, é mutilado e fraturado por um trabalho parcial. Já na maquinaria, a dependência das habilidades e do virtuosismo do trabalhador é superada. Devido ao avanço e à aplicação dos conhecimentos científicos, a ferramenta se transfere do ser humano para um mecanismo e ascende em termos sociais a volúpia da produção mecanizada. Qual formação humana caracteriza a maquinaria? Trata-se também de uma formação unilateral, mas com características diferentes do período da manufatura. Com a produção mecanizada, o saber que possuía o trabalhador é materializado na máquina, 
cabendo a ele apenas operá-la a partir do ritmo ditado por ela. Nesse processo, o trabalhador é despojado do saber de um trabalho concreto; cabe a ele apenas manusear a máquina, sem necessariamente compreendê-la. O ser humano torna-se um servo da máquina e sem dominar os conhecimentos científicos e tecnológicos que nela se materializam.

$\mathrm{Na}$ condição de fragmento vivo de um mecanismo morto (máquina), o trabalhador vive uma alteração nas suas tarefas. Na manufatura, o trabalhador despendia longos anos para alcançar o virtuosismo de uma operação isolada e nela permanecia por toda sua vida. A maquinaria desfere um golpe mortal a essa lógica, pois, ao transferir para a máquina a ação de agir sobre objeto, despede-se do tempo de aprendizagem para a conquista da excelência em uma tarefa específica. As funções do trabalhador se tornam mais variadas e fluidas em decorrência da sua maior mobilidade. O seu trânsito entre diferentes funções e ramos da produção demanda dele maior versatilidade, fluidez, plasticidade para se adaptar a novas operações. $\mathrm{O}$ horizonte de formação passa a ser o da pluriprofissionalidade e da multifuncionalidade.

Apesar de toda estreiteza dessa formação, Marx enxerga nela gérmens do que ele chama formação omnilateral. Como isso é possível? Que gérmens são esses? O que Marx chama de formação omnilateral?

\section{FORMAÇÃO OMNILATERAL E A "EDUCAÇÃO DO FUTURO"}

Usado pela primeira vez por Marx em referência à formação humana nos Manuscritos econômico-filosóficosde 1844, o termo omnilateral (cujo correspondente alemão éallseitig e suas variações) vincula-se ao devir comunista. De acordo com Marx, a essência humana se desdobra para fora de si e constitui novas objetividades. Nesse objetivar-se, o ser humano se afirma no mundo objetivo "Não só no pensamento [...], mas com todos os sentidos [...]" (MARX, 2004, p. 110). Se o ser humano projeta a sua essência (aquilo que é) no que produz de modo omnilateral (inteiro), o comunismo representa a possibilidade de ele apropriar-se disso que ele produziu (da sua essência materializada nas produções culturais) de modo pleno, inteiro, omnilateralmente.

É sob a nova sociabilidade comunista que Marx vislumbra a emancipação humana: "Qualquer emancipação constitui uma restituição do mundo humano e das 
relações humanas ao próprio homem" (MARX, 2002, p. 37). Portanto, a emancipação diz respeito a um novo arranjo social no qual o ser humano é fim de si mesmo e não meio. Fala-se, assim, não apenas de emancipação de todos os seres humanos, mas também de emancipação do ser humano por inteiro. Em contraste com o ser humano fraturado pela divisão social do trabalho, coloca-se o ser humano total, omnilateral, em todas as capacidades e faculdades. Sob esse pressuposto, Marx entrevê o enriquecimento da essência humana. Segundo ele (2004, p. 161), o ser humano rico e emancipado tem o outro como necessidade de seu existir, é educado para usufruir a arte, apreciar a beleza, agir de modo estimulante e encorajador sobre os outros, trocar amor por amor.

O termo allseitig/omnilateral e suas variações continuaram a ser usadas por Marx em obras subsequentes aos Manuscritos, mas com uma novidade: com o amadurecimento das reflexões marxianas, ele também é usado com frequência para adjetivar aspectos do capitalismo ou exprimir modos de sua atuação e sua repercussão na formação humana. Dito de outra maneira, o termo passou a ganhar a natureza contraditória de vincular-se à dinâmica capitalista e também à sua superação.

Para evidenciar isso, tomo o exemplo do uso que Marx faz do termo omnilateral para explicar o caráter de produção mundializada do capitalismo. Nesse caso, o termo alemão correspondente à omnilateral aparece também traduzido como universal e mundial. Marx observa que o esforço do capital é libertar-se de quaisquer obstáculos para sua autovalorização; por isso, a necessidade de derrubar barreiras locais de troca e reduzir o tempo de movimento de um local a outro.

A sociedade burguesa constitui, pela primeira vez na história, “[...] um sistema de metabolismo social universal, de relações universais, de necessidades múltiplas [allseitigerBedürfnisse] e de capacidades universais" (MARX, 2011, p. 106).

Porque o intercâmbio e as forças produtivas são universais (omnilaterais), só podem ser apropriadas por indivíduos universalmente desenvolvidos. Ademais, "O moderno intercâmbio universal não pode ser subsumido aos indivíduos senão na condição de ser subsumido a todos" (MARX; ENGELS, 2007, p. 73). Mas o desenvolvimento universal/pleno dos indivíduos é condição para a superação da propriedade privada. Por sua vez, a propriedade privada torna-se, nesse processo, um 
empecilho. Assim, o capital traz em si o potencial de seu além, mas, ao mesmo tempo, o represa.

O comunismo se coloca, assim, como "A realização do indivíduo em todos os seus aspectos", momento no qual “[...] os indivíduos singulares são libertados das diversas limitações nacionais e locais, são postos em contato prático com a produção (incluindo a produção espiritual) do mundo inteiro e em condições de adquirir a capacidade de fruição dessa multifacetada produção de toda a terra (criações dos homens)" (MARX; ENGELS, 2007, p. 41).

Marx discute, de modo breve, n'O Capital, a forma escolar correspondente à formação omnilateral: "Do sistema fabril, [...] brotou o germe da educação do futuro que conjugará o trabalho produtivo de todos os meninos além de uma certa idade com o ensino e a ginástica, constituindo-se em método de elevar a produção social e de único meio de produzir seres humanos plenamente desenvolvidos” (MARX, 1985, p. 554, grifo meu).

Manacorda (2011) observa que a defesa de uma formação ampla que se efetivasse pela junção entre trabalho e educação compôs, desde o início do século XIX, a tradição pedagógica dos socialistas utópicos. Contudo, observa esse autor, Marx reconheceu que a fórmula de conjugar escola e trabalho também se efetivou sob os interesses burgueses. O seu marco foram as leis fabris na Inglaterra. A proposta burguesa de conjugar escola e trabalho responde à necessidade de formar um trabalhador apto a transitar em diversos ramos da produção. Trata-se de um treinamento técnico circunscrito à fluidez de funções e à mobilidade do trabalhador. Contudo, ao assegurar a obrigatoriedade da educação de crianças empregadas nas fábricas, as leis fabris abriram, mesmo dentro dos moldes capitalistas, uma possibilidade de conjugar capacidades humanas diversas.

Aproveitando-se dessa fissura que abre a própria dinâmica capitalista, Marx insiste em uma educação ampla e alinha, assim, a educação escolar à luta política relativa ao controle da produção e dos conhecimentos que lhe servem de alicerce. Ao incluir naquilo que ele visualiza ser um projeto escolar orientado pela formação omnilateral o vínculo do trabalho produtivo, com a educação intelectual e corporal/estético-artística, ele se apropria do que há de mais avançado no impacto da 
maquinaria sobre a formação do trabalhador como ponto de partida para a "educação do futuro".

\section{CONSIDERAÇÕES FINAIS}

Como visto, a formação humana se dá no trabalho, porque, no fundo, o trabalho é, ele próprio, agir formativo. Ao mesmo tempo que cria, o trabalho também estipula exigências aos indivíduos em seu processo de produzir a vida, define qualidades, habilidades requeridas para a participação em um certo modo de viver. Nesse sentido, há uma formação para o trabalho. Em síntese e considerando que a formação coincide com o sentido amplo de educação, podemos afirmar junto com Saviani: a educação/ formação é posta pelo trabalho e, de modo dialético, aparece como "[...] uma exigência do e para o processo de trabalho" (SAVIANI, 1991, p. 19).

Se, no capitalismo, o trabalho forma e deforma, assumir a relação entre trabalho e formação implica, a meu ver, defender o trabalho como princípio educativo na sua existência contraditória de efetivar e desefetivar o ser humano. Sob essa ótica, formar para o trabalho pode ter um significado geral e outro mais específico. Em termos gerais, implica recuperar, por meio do processo formativo intencional, a ação humana criativa e criadora, oser humano como agente de sua história e de seu fazer-se. Sem essa faceta, não há chance de colocar na agenda de luta projetos revolucionários. Isso significa, por exemplo, tratar o saber escolar como produções humanas, expressão de modos de viver e se tornar humano em um dado momento, expressão do conjunto de relações sociais que se estabelecem ao se produzir a vida, do conflito entre produzir e usufruir a riqueza humana materializado no patrimônio cultural.Apropriar-se desse saber em uma perspectiva histórico-crítica é, de alguma forma, desterrar essa história.

De um modo mais específico, formar para o trabalho significa compreender o que e como produzimos nossa vida no capitalismo. Em outros termos, coloca-se a tarefa de criticar o trabalho na sua forma alienada, assim como identificar e se apropriar dos avanços que nele se materializam. Interessa o domínio crítico das formas mais avançadas de conhecimento, tecnologia, formas de sentir, habilidades etc. que se condensam nessa forma social do trabalho explorado. 
A "educação do futuro" (a partir dos interesses dos trabalhadores) nasce ainda sob a hegemonia burguesa e, enquanto essa hegemonia não for superada, ela não se plenifica. Nossa tarefa, portanto, é tomar essa brecha queo capital libertou, mas, ao mesmo tempo, tenta barrar. Para tanto, qualquer teoria educacional contra hegemônica precisa abraçar como norte a emancipação da humanidade no seu conjunto e uma formação na qual não haja hierarquia de faculdades e capacidades humanas, uma formação que articule (e não interponha) as dimensões intelectual, estético-artística, ética, políticaa partir do trabalho.

No contexto de ataquesa quaisquer faíscas de defesa dos direitos humanos e de criticidade, de um governo golpista vigentee de um governo vindouro, de cunho totalitário, reacionário, precisamos bradar que temos o direito de sermos grandes, nos moldes dos versos de Fernando Pessoa: "Para ser grande, sê inteiro: nada/ Teu exagera ou exclui./ Sê todo em cada coisa. Põe quanto és/ No mínimo que fazes./ Assim em cada lago a lua toda. Brilha, porque alta vive”. E ousemos adicionar à poesia de Pessoa o excerto da música que protesta: "A gente quer inteiro e não pela metade" (Comida, Titãs).

E de onde virão as primeiras melodias dessa música ou os primeiros versos desse poema? Daqueles que, mesmo enfrentando vários obstáculos, estão ensaiando, inventando, experimentando, tateando caminhos, estratégias e ações de uma educação integrada... virão dos que estão, com muito custo, abrindo caminhos para a "educação do futuro". Desde seu estabelecimento em 2008, os Institutos Federais de Educação, Ciência e Tecnologia têm ensaiadoexperiências nesse horizonte político-pedagógico. Por essa condição de ensaio e mesmo com todas as contradições que, por vezes, fragilizam ou esvaziam a proposta de integrar formação humana e técnica, considero que, os Institutos Federais de Educação, Ciência e Tecnologia (IF's) podem assumir um lugar de vanguarda como agente de luta. Acredito que dos IF's virá o primeiro grito poético e musical ao qual aludi.Nenhum retrocesso em nosso frágil, mas evidente avanço rumo à “educação do futuro"! 


\section{REFERÊNCIAS}

ALBORNOZ, Suzana. O que é trabalho. 6.ed. São Paulo: Brasiliense, 2000.

ENGEL, F. Quota-parte do trabalho na hominização do macaco. In: MARX, K.; ENGELS, F. Obras escolhidas. Lisboa: Edições Avante! Edições Progresso, 1985.p. 71-83. Tomo 3.

HEGEL, Georg Wilhelm. Fenomenologia do espírito. 6. Ed. Petrópolis: Vozes, 2011.

HENRY, Michel. O socialismo na obra de Marx. Rio de Janeiro: Contraponto, 2015.

HESÍODO.Os trabalhos e os dias. Curitiba: Segesta, 2012.

LESSA, Sergio. Trabalho e proletariado no capitalismo contemporâneo. São Paulo: Cortez, 2007.

MANACORDA, Mário A. Marx e a formação do homem. Revista HISTEDBR Online, Campinas, v. 11, n. 41e (número especial), p. 6-15, abr. 2011.

MANACORDA, Mário A. História da educação. 5. ed. São Paulo: Cortez, 1996.

MARX, Karl. A questão judaica. In: . Manuscritos econômico-filosóficos. São Paulo: Martin Claret, 2002. p. 13-44.

MARX, Karl. Grundrisse. São Paulo/ Rio de Janeiro: Boitempo/UFRJ, 2011.

MARX, Karl. O capital (livro 1).10. ed. São Paulo: Difel, 1985b. v. I e II.

MARX, Karl; ENGELS, Friedrich. A ideologia alemã: crítica da mais recente filosofia alemã em seus representantes Feuerbach, B. Bauer e Stirner, e do socialismo alemão em seus diferentes profetas (1845-1846). São Paulo: Boitempo, 2007.

MOURA, Alessandro Rolim de. Introdução. In: HESÍODO.Os trabalhos e os dias. Curitiba: Segesta, 2012. p. 11-55.

NOSELLA, P. Trabalho e perspectivas de formação dos trabalhadores: para além da formação politécnica. Revista Brasileira de Educação, Rio de Janeiro, v. 12, n. 34, p.137-151, abr. 2007.

ROSSI, Paolo. O nascimento da ciência moderna na Europa. Bauru: Edusc, 2001.

SAVIANI, Dermeval. O choque teórico da politecnia. Trabalho, Educação e Saúde, Rio de Janeiro, v. 1, n. 1, p. 131-152, 2003.

SAVIANI, Dermeval. História das ideias pedagógicas no Brasil. Campinas: Autores Associados, 2007. 
SAVIANI, Dermeval. Pedagogia histórico-crítica: primeiras aproximações. São Paulo: Cortez/ Autores Associados, 1991.

TUMOLO, Paulo Sérgio. O trabalho na forma social do capital e o trabalho como princípio educativo: uma articulação possível? Educação \& Sociedade, Campinas, v. 26, n. 90, p. 239-265, jan./abr. 2005.

WEBER, Max. A ética protestante e o espírito do capitalismo. 5 e. São Paulo: Pioneira, 1987. 